\title{
Parity and lodine Status are Predictive Factors for Goitre Prevalence in Females
} \author{
Rema Markous ${ }^{1}$, Kevan Farahati ${ }^{1}$ and Rasoul S Zakavi ${ }^{4}$ \\ ${ }^{1}$ Clinic for Nuclear Medicine, Bethesda, Duisburg, Germany \\ ${ }^{2}$ Clinic and Policlinic for Nuclear Medicine, University Hospital Essen, Germany \\ ${ }^{3}$ Endocrine Research Center, Mashhad University of Medical Sciences, Mashhad, Iran \\ ${ }^{4}$ Nuclear Medicine Research Center, Mashhad University of Medical Sciences, Mashhad, Iran
}

Jamshid Farahati1,2*, Rainer Görges², Elana Gillman", James Nagarajah², Zohre Mousavi",

Corresponding author: Jamshid Farahati, Associate Professor, Clinic for Nuclear Medicine, Bethesda, Duisburg, Germany, Dorsten, Heerstr 219, 47053 Duisbrg, Germany, Tel: +49-203- 6008-1451; Fax: +49-203-6008-1499; E-mail: j.farahati@bethesda.de

Received: Jul 29, 2016; Accepted: Aug 31, 2016; Published: Sep 02, 2016

Citation: Farahati J, Görges R, Gilman E, et al. Parity and lodine Status are Predictive Factors for Goitre Prevalence in Females. Transl Biomed. 2016, 7:3.

\section{Abstract}

Background: To evaluate the predictive factors of goitre prevalence in females.

Methods: In a questionnaire-based survey, data from 370 female employees aged between from 4 institutions in western part of Germany was collected between April 2001 and April 2002 and the association between parity and simple goitre was examined with respect to age, daily use of iodized salt, contraceptives, the history of goitre in the first degree relatives and smoking. Ultrasound of the neck was performed in all cases to determine the thyroid volume. Logistic regression analyses were performed to adjust for age, iodine status, parity, contraceptives, familial history of goitre and smoking.

Results: The overall prevalence of goitre was (80/370) $21.6 \%$. Median thyroid volume Goitre was present in 44 out of 140 parous (31.4\%) vs. $34 / 220$ (15.5\%) in nulliparous (odds ratio: $2.5 ; p<0.001$ ). Indeed, the linear regression shows a positive association of the thyroid volume with increasing age $(p=0.023)$, the number of cigarettes in a week $(p=0.001)$ and its negative association with duration of contraceptive intake $(p=0.005)$, no association with iodine intake or parity could be detected. However, the logistic regression analysis revealed significant association only between goitre prevalence and parity $(p=0.004)$, and lack of daily iodized salt intake $(p=0.01)$, whereas, age $(p=0.18)$, contraceptive $(p=0.82)$, the familial history of goitre $(p=0.33)$ and smoking $(p=0.09)$ did not affect the goitre prevalence.

Conclusions: Parity and iodine status are predictive factors of goitre prevalence in females.

Keywords: Thyroid; Goiter; lodine; Smoking; Male

\section{Introduction}

Despite recent improvement of iodine supplementation since 1989 [1-6] the prevalence of goitre in Germany remains substantial [7-9]. The etiology of simple endemic or sporadic goitre depends on genetic and environmental factors. Indeed, the major factor remains iodine deficiency $[9,10]$. However, thyroid disorders occurs predominantly in females [11,12], suggesting that hormonal determinants are involved in pathogenesis of this disease.

An association between parity and the risk of goitre is reported in some, but not all studies [13-15]. In this prospective study, we investigated the predictive factors of simple goitre in females with respect to parity, age, daily use of iodized salt, contraceptives, the history of goitre in the first degree relatives and smoking in $\mathbf{3 7 0}$ healthy females.

\section{Materials and Methods}

Study DesignBetween April 2001 and April 2002, a total of 370 healthy female employees of 4 institutions in Essen (Bethesda Essen and Karstadt AG) and Muelheim (Siemens AG and Mannesmann AG) in western part of Germany aged between 18 and 68 years (range: $41.0 \pm 10.0$ y) were examined by ultrasound of the neck to determine the thyroid volume.Ultrasound was performed by one experienced investigator (J.F.) with a Siemens Sonoline SI-400 using a 7.5 $\mathrm{MHz}$ linear scanner. The ultrasound was performed according to standardized criteria and the volume of thyroid was determined as the sum of / $6 \times$ length $\times$ width $\times$ depth of both lobes. Goitre was defined as a thyroid volume exceeding 18 $\mathrm{ml}$.All subjects with present or former thyroid disorder were excluded from this analysis. Information on date of birth, date of screening, sex, daily use of iodized salt, history of previous diseases including benign diseases of thyroid, history of thyroid disorders in the first degree relatives, type and amount of smoking, contraceptives, and parity were assessed by standardized questionnaires.StatisticsThe general descriptive analyses were performed using PASW Statistics (Version 19.0). 
Values for continuous variables are given as means SD. Statistical differences between groups and comparison of frequencies of goitre between groups were calculated with the Chi-Square test.Linear and logistic regression analyses were performed to adjust for age, smoking, iodine status, parity, use of contraceptives and familial history of goitre. Parameters were estimated using a least squares and a maximumlikelihood methods and the significance level was assessed using F- and Wald tests respectively. A p-value below 0.05 was considered to be statistically significant.

\section{Results}

The overall prevalence of goitre was (80/370) $21.6 \%$. Median thyroid volume among parous $(16.3 \pm 7.4 \mathrm{ml})$ was higher as compared to nulliparous females $(14.2 \pm 6.0 \mathrm{ml})$. Goitre was present in 24 out of 62 (38.7\%) bi-parus versus $20 / 78$ (25.6\%) uniparus females and versusvs. 34/219 (15.5\%) in nulliparous (Figure 1). The risk of goitre in biparus females was 3.4 times higher as compared to nulliparus females and 1.9 fold than uniparus females.

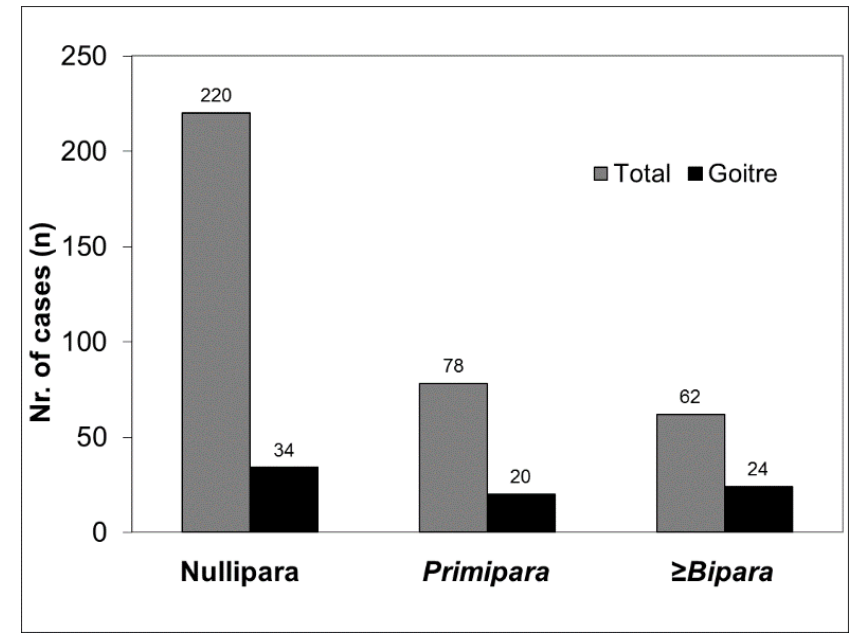

Figure 1 Goitre frequency (black column) among 360 (white column) nullipara, primipara and bipara females. The number of cases does not reach the total number of cases because of missing data.

Indeed, the linear regression shows a positive association of the thyroid volume with increasing age $(p=0.023)$, the number of cigarettes in a week $(p=0.001)$ and its negative association with duration of contraceptive intake $(p=0.005)$, but no association with iodine intake or parity could be detected.However, the logistic regression analysis (Table 1) revealed significant association only between goitre prevalence and parity $(p=0.004)$, and lack of daily iodized salt intake $(p=0.01)$, whereas, age $(p=0.18)$, contraceptive $(p=0.82)$, the familial history of goitre $(p=0.33)$ and smoking $(p=0.09)$ did not affect the goitre prevalence.

Table 1 Association of age, smoking, daily use of iodized salt, parity, contraceptives and familial history of thyroid disorders with goitre prevalence assessed by logistic regression analysis in 370 healthy females.

\begin{tabular}{|c|c|c|c|c|}
\hline & $\begin{array}{l}\text { Number of } \\
\text { cases } n\end{array}$ & $\begin{array}{l}\text { Goitre n } \\
(\%)\end{array}$ & $\begin{array}{l}\text { Adjusted odds ratio } \\
\left(95 \% \mathrm{Cl}^{* *}\right)\end{array}$ & $\begin{array}{l}\text { Wald } \\
\text { Test } p\end{array}$ \\
\hline $\begin{array}{l}\mathrm{A} \\
\mathrm{g} \\
\mathrm{e}\end{array}$ & & & $1.02(0.99 ; 1.05)$ & 0.18 \\
\hline \multicolumn{5}{|c|}{ Smoking } \\
\hline+ & 149 & $\begin{array}{l}38 \\
(25.5 \%)\end{array}$ & $1.59(0.93 ; 2.70)$ & \multirow[t]{2}{*}{0.09} \\
\hline - & 221 & $\begin{array}{l}42 \\
(19.0 \%)\end{array}$ & & \\
\hline
\end{tabular}

lodized salt

\begin{tabular}{|c|c|l|l|c|}
\hline+ & 204 & $\begin{array}{l}38 \\
(18.6 \%)\end{array}$ & $0.50(0.29 ; 0.85)$ & 0.01 \\
\hline- & 165 & $\begin{array}{l}42 \\
(25.5 \%)\end{array}$ & & \\
\hline
\end{tabular}

Parity

\begin{tabular}{|c|c|c|c|c|}
\hline+ & 140 & $\begin{array}{l}44 \\
(31.4 \%)\end{array}$ & $2.39(1.32 ; 4.31)$ & 0.004 \\
\hline- & 220 & $\begin{array}{l}34 \\
(15.5 \%)\end{array}$ & \\
\hline+ & 187 & $\begin{array}{l}36 \\
(19.3 \%)\end{array}$ & $0.94(0.55 ; 1.60)$ & 0.82 \\
\hline \multicolumn{2}{|l|}{ Contraceptives } & $\begin{array}{l}44 \\
(24.0 \%)\end{array}$ & \\
\hline
\end{tabular}

Family history

\begin{tabular}{l|l|l|l|l}
\hline+ & 133 & $\begin{array}{l}30 \\
(22.6 \%)\end{array}$ & $1.32(0.76 ; 2.27)$ & 0.33 \\
\hline- & 237 & $\begin{array}{l}50 \\
(21.1 \%)\end{array}$ & \\
\cline { 1 - 2 } & & &
\end{tabular}

*Number of cases does not reach the total number in all groups because of missing data

${ }^{* *} \mathrm{Cl}$ : confidence interval.

\section{Discussion}

Goitre is a major health problem in Germany and the annual costs for treatment of goitre and is estimated at 1 billion Euros [9]. Despite recent improvement of iodine supplementation since 1989 [1-6], the prevalence of goitre in Germany remains substantial [7-9]. The etiology of simple endemic or sporadic goitre depends on genetic and environmental factors. Indeed, the major factor remains iodine deficiency $[9,10]$. However, thyroid disorders occur predominantly in females [11,12], which are attributed to endogenous hormones during puberty and pregnancy.

lodine supplementation during pregnancy can reduce the goitre prevalence among parous females [11]. In agreement, in our linear regression and logistic regression analyses lack of daily intake of iodized salt increase the prevalence of goitre, however, parity remained the major factor implicating the goitre prevalence. The risk of the developing goitre in 
multiparous women was more than 3 times higher as compared to nulliparous women.

In agreement with our finding, Rotondi et al. report on association between parity and thyroid volume in an area with moderate iodine deficiency [13]. In contrast, Gomez et al. found no association between thyroid volume and parity among 134 randomly selected healthy females [14].

Knudsen et al. report in a recent publication on association between increased thyroid volume only among smokers, more pronounced in iodine deficient area [15].

The association between smoking and goitre prevalence in females is discussed controversial [16-18]. However, we found in our analysis only an association linear regression analysis, but the effect of smoking on goitre prevalence in females could not be approved by logistic regression analysis. In contrast, Christensen et al. [17] evaluated the prevalence of goitre by palpation in 441 middle aged women and found higher goitre prevalence among smokers (14.8\%) as compared to ex-smokers (3.8\%) and non-smokers (9.4\%). Ericsson et al. [18] reported a higher goitre prevalence among smoking females (14.2\%) as compared to non-smokers (8.9\%) and exsmokers (7.0\%) in an epidemiological study from Sweden including more than 4000 subjects. In contrast, Petersen et al. [19] found no increased prevalence of thyroid disease or goitre in 1154 middle-aged and older Swedish women with respect to smoking (14.3\% smokers vs. $13.4 \%$ non-smokers).

Here it can be concluded from our research that the parity and iodine status are the major factors associating with the prevalence of goitre in females.

\section{Acknowledgement}

We thank Dr. Eberhard Heissen, Mrs. Vo and Mrs. Walschus for preparing the manuscript.

\section{References}

Hampel R, Gordalla A, Zollner H, Klinke D, Demuth M (2000) Continuous rise of urinary iodine excretion and drop in thyroid gland size among adolescents in Mecklenburg-West-Pomerania from 1993 to 1997. Exp Clin Endocrinol Diabetes 108: 197-201.

2. Hampel R, Beyersdorf-Radeck B, Below $H$, Demuth $M$, Seelig $K$ (2001) Urinary iodine levels within normal range in German school-age children. Med Klin 96: 125-128.

Meng W, Schindler A, Horack S, Lux E, Muche A (1998) Rena iodine excretion by students in East Germany. A prospective study 1989 to 1996 . Med Klin 93: 347-351.

Gartner R, Manz F, Grossklaus R (2001) Representative data of iodine intake and urinary excretion in Germany. Exp Clin Endocrinol Diabetes 109: 2-7.

Rendl J, Juhran N, Reiners C (2001) Thyroid volume and urinary iodine in German school children. Exp Clin Endocrinol Diabetes 109: 8-12.
Manz F, Bohmer T, Gartner R, Grossklaus R, Klett M, et al. (2002) Quantification of iodine supply: representative data on intake and urinary excretion of iodine from the German population in 1996. Ann Nutr Metab 46: 128-138.

Volzke H, Ludemann J, Robinson DM, Spieker KW, Schwahn C, et al. (2003) The prevalence of undiagnosed thyroid disorders in a previously iodine-deficient area. Thyroid 13: 803-810.

Gartner R, Bechtner G, Rafferzeder M, Greil W (1997) Comparison of urinary iodine excretion and thyroid volume in students with or without constant iodized salt intake. Exp Clin Endocrinol Diabetes 105: 443- 45.

Kahaly GJ, Dietlein M (2002) Cost estimation of thyroid disorders in Germany. Thyroid 12: 909- 914.

10. Farahati J, Geling M, Mader U, Mortl M, Luster M, et al. (2004) Changing trends of incidence and prognosis of thyroid carcinoma in "Lower Frankonia", Germany from 1981-1995. Thyorid 14: 139-145.

11. Glinoer D, De Nayer P, Delange F, Lemone $M$, Toppet $V$, et al. (1995) A randomised trial for the treatment of mild iodine deficiency during pregnancy: maternal and neonatal effects. J Clin Endocrinol Metab 80: 258-269.

Farahati J, Bucsky P, Parlowsky TH, Mader U, Reiners C (1997) Characteristics of differentiated thyroid cancer in children and adolescents with respect to age, gender and histology. Cancer 80: 2156-2162.

Rotondi M, Amato G, Biondi B, Mazziotti G, Del Buono A, et al. (2000) Parity as a thyroid size-determining factor in areas with moderate iodine deficiency. J Clin Endocrinol Metab 85: 4534-4537.

Gomez JM, Maravall FJ, Gomez N, Guma A, Soler J (2000) Determinants of thyroid volume as measured by ultrasonography in healthy adults randomly selected. Clin Endocrinol 53: 629-634.

Knudsen N, Bulow I, Laurberg P, Ovesen L, Perrild H, et al. (2002) Parity is associated with increased thyroid volume solely among smokers in an area with moderate to mild iodine deficiency. Eur J Endocrinol 146: 39-43.

Bertelsen JB, Hegedus L (1994) Cigarette smoking and the thyroid. Thyroid 4: 327-331.

7. Christensen SB, Ericsson UB, Janzon L, Tibblin S, Melander A (1984) Influence of cigarette smoking on goiter formation, thyroglobulin, and thyroid hormone levels in women. J Clin Endocrinol Metab 58: 615-618.

18. Ericsson UB, Lindgarde $F$ (1991) Effects of cigarette smoking on thyroid function and the prevalence of goitre, thyrotoxicosis and autoimmune thyroiditis. J Intern Med. 229 67-71.

Petersen K, Lindstedt G, Lundberg PA, Bengtsson C, Lapidus L, et al. (1991) Thyroid disease in middle-aged and elderly Swedish women: thyroid-related hormones, thyroid dysfunction and goitre in relation to age and smoking. J Intern Med 229: 407-413. 